\title{
Blue Rubber Bleb Nevus Syndrome Showing Vascular Skin Lesions Predominantly on the Face
}

\author{
Ayumi Korekawa Koji Nakajima Takayuki Aizu Hajime Nakano \\ Daisuke Sawamura \\ Department of Dermatology, Hirosaki University Graduate School of Medicine, \\ Hirosaki, Japan
}

\section{Key Words}

Venous malformation · Gastrointestinal bleeding · Trauma $\cdot$ Lower leg

\begin{abstract}
An 81-year-old Japanese man presented with dark blue papules and nodules on his face. There were multiple soft papules and nodules, dark blue in color, compressive, and ranging in size from 2 to $10 \mathrm{~mm}$. A few similar lesions were seen on the patient's right dorsal second toe and right buccal mucosa. There were no skin lesions on his trunk and upper limbs. The patient's past history did not include gastrointestinal bleeding or anemia. Histopathological examination showed dilated vascular spaces lined by the normal epithelium extending beneath the dermis and into the subcutaneous fat. Endoscopy of the gastrointestinal tract to check for colon involvement was not performed. X-ray images of the limbs revealed no abnormalities in the bones or joints. Laboratory investigations did not show anemia. Although we failed to confirm a diagnosis by endoscopy, the skin lesions, histopathological findings, lack of abnormal X-ray findings, and the presence of oral lesions as a part of gastrointestinal tract guided the diagnosis of blue rubber bleb nevus syndrome (BRBNS). Skin lesions of BRBNS occur predominantly on the trunk and upper limbs. However, the present case showed multiple skin lesions predominantly on the face. Therefore, it is important for clinicians to know about a possible atypical distribution of skin lesions in BRBNS.
\end{abstract}


Korekawa et al.: Blue Rubber Bleb Nevus Syndrome Showing Vascular Skin Lesions Predominantly on the Face

\section{Introduction}

Blue rubber bleb nevus syndrome (BRBNS) is a rare disorder characterized by venous malformations of the skin and internal organs, especially in the gastrointestinal (GI) tract. The skin lesions may appear anywhere on the body but predominantly occur on the trunk and upper limbs. We describe a case of BRBNS occurring mainly on the face of an 81-yearold Japanese man.

\section{Case Report}

An 81-year-old Japanese man presented with dark blue papules and nodules on his face. He had observed the skin lesions on his face for years earlier; however, they had gradually increased in number during the previous 2 months. On physical examination, there were multiple compressive soft papules and nodules on his face, dark blue in color, with smooth surfaces, and ranging in size from 2 to $10 \mathrm{~mm}$ (fig. 1). A few similar lesions were seen on the patient's right dorsal second toe and right buccal mucosa (fig. 2). There were no skin lesions observed in other regions, including the patient's head, trunk, upper limbs, thighs, lower legs, and genital region. There was also no associated pain and hyperhidrosis. The patient's medical history included an operation (excision and skin graft) for a cutaneous hemangioma on the right dorsal foot during his youth. However, the patient did not have a history of GI bleeding, melena, or anemia. His family reported no history of vascular lesions.

We performed a skin biopsy of a lesion located on the patient's left cheek. Histopathological examination showed dilated vascular spaces lined by normal epithelium in the dermis. The vascular space was surrounded by thin connective tissue. Lysed erythrocytes were present within the vascular space (fig. $3 \mathrm{a}-\mathrm{c}$ ). Glomus cell growth, sweat gland proliferation, thrombosis, and calcification were not seen.

Endoscopy of the GI tract to check for colon involvement was not performed, because the patient was asymptomatic and he was not willing to undergo endoscopic investigation. $\mathrm{X}$-ray images of the limbs revealed no abnormalities in the bones or joints. Laboratory tests were within normal ranges expected for mild low serum iron levels $(48 \mu \mathrm{g} / \mathrm{dl}$, normal range $60-150 \mu \mathrm{g} / \mathrm{dl})$.

Although we failed to confirm a diagnosis by endoscopy, the skin lesions, histopathological findings, lack of abnormal X-ray findings, as well as the presence of oral lesions as the GI tract lesions led to the diagnosis of BRBNS. We recommended therapy including an operation and cryotherapy; however, the patient refused therapy citing old age.

\section{Discussion}

Gascoyen [1] first described an association between cavernous hemangiomas (nevi) of the skin and similar lesions of the intestine with GI bleeding. In reference to this condition, Bean [2] further coined the term 'blue rubber bleb nevus syndrome' (also known as Bean syndrome). BRBNS is often diagnosed during childhood and young adulthood. Skin lesions are usually asymptomatic and characterized by the appearance of blue papules with rubberlike nipples that are easily compressive and refill slowly upon release of pressure.

As with skin lesions, hemangiomas occur predominantly on the trunk and upper limbs. Deng et al. [3] described the sites where skin lesions typically appear, including the trunk (93\%), limbs (86\%), hip (36\%), and face (26\%). In the present case, there were multiple 
Korekawa et al.: Blue Rubber Bleb Nevus Syndrome Showing Vascular Skin Lesions Predominantly on the Face

skin lesions growing predominantly on the face. There were only a few lesions on the patient's right dorsal foot and no lesions on his trunk and upper limbs. Distribution on the face and foot is extremely rare.

Involvement of the internal organs of the GI tract is also very common, particularly the small intestine. However, involvement of other organs has often been described, including the liver, spleen, kidneys, adrenal grand, heart, lung, penis, bladder, ocular orbit, thyroid, muscle, central nervous system, and brain. Hemangiomas of the GI tract often induce irondeficiency anemia, GI bleeding, and melena [4,5]. A tendency for thrombosis of venous malformation was described in the brain and systemic organs, and hemorrhaging from vascular lesions of the brain was reported to cause ataxia, dementia, and focal neurologic signs $[6,7]$.

There are three types of BRBNS lesions (table 1) [2]. Type II is the most common type of lesion, and a patient can often have overlapping types. In the present case, we estimated that type II was appropriate because there were multiple, dark blue, compressive papules and nodules on the patient's face, ranging in size from 2 to $10 \mathrm{~mm}$.

While autosomal dominant inheritance has been reported, most cases of BRBNS occur spontaneously, as in the present case. The pathogenesis of BRBNS remains unclear; however, it has been suggested that a locus on chromosome 9P responsible for venous malformation and elevated c-kit expression may be involved [8, 9]. Although BRBNS is an uncommon syndrome, physical examination of the patient, GI imaging tests, and circumstantial questioning can help make a diagnosis. While the present case did not show GI bleeding, we suggest that careful attention be paid to BRBNS because of the potential for causing fatal bleeding.

\section{Statement of Ethics}

The authors state that the patient gave his informed consent, and the informed consent was in accordance with the guidelines approved by Hirosaki University Graduate School of Medicine.

\section{Disclosure Statement}

The authors declare no conflicts of interest.

\section{References}

1 Gascoyen M: Case of naevus involving the parotid gland and causing death from suffocation: naevi of the viscera. Trans Pathol Soc 1860;11:267.

2 Bean WB: Blue rubber-bleb nevi of the skin and gastrointestinal tract; in Bean WB (ed): Vascular Spiders and Related Lesions of the Skin. Springfield, Charles C. Thomas, 1958, pp 17-185.

3 Deng ZH, Xu CD, Chen SN: Diagnosis and treatment of blue rubber bleb nevus syndrome in children. World J Pediatr 2008;4:70-73.

4 Nahm WK, Moise S, Eichenfield LF, Paller AS, Nathanson L, Malicki DM, Friedlander SF: Venous malformations in blue rubber bleb nevus syndrome: variable onset of presentation. J Am Acad Dermatol 2004;50(5 suppl):S101-S106.

5 Suma GN, Ravi Prakash SM, Rao D, Goel S: Blue rubber bleb nevus syndrome: prominent oral findings. Indian J Dermatol Venereol Leprol 2010;76:168-171.

-6 Waybright EA, Selhorst JB, Rosenblum WI, Suter CG: Blue rubber bleb nevus syndrome with CNS involvement and thrombosis of a vein of galen malformation. Ann Neurol 1978;3:464-467. 


\section{Case Reports in Dermatology}

\begin{tabular}{l|l}
\hline \multicolumn{2}{l|}{ Case Rep Dermatol 2015;7:194-198 } \\
\hline DOI: $10.1159 / 000438664$ & $\begin{array}{l}\text { C } 2015 \text { S. Karger AG, Basel } \\
\text { www.karger.com/cde }\end{array}$ \\
\hline
\end{tabular}

Korekawa et al.: Blue Rubber Bleb Nevus Syndrome Showing Vascular Skin Lesions Predominantly on the Face

7 Vig EK, Brodkin KI, Raugi GJ, Gladstone H: Blue rubber bleb nevus syndrome in a patient with ataxia and dementia. J Geriatr Psychiatry Neurol 2002;15:7-11.

8 Mogler C, Beck C, Kulozik A, Penzel R, Schirmacher P, Breuhahn K: Elevated expression of c-kit in small venous malformations of blue rubber bleb nevus syndrome. Rare Tumors 2010;2:e36.

9 Liu Q, Chen YP, Li YM: Blue rubber bleb nevus syndrome: a report of one case associated with recurrent epistaxis. Chin Med J (Engl) 2007;120:731-733.

Table 1. Classification of BRBNS

\begin{tabular}{ll}
\hline Type & Clinical findings \\
\hline I & $\begin{array}{l}\text { Large disfiguring venous malformation that obstructs vital } \\
\text { tissues }\end{array}$ \\
\hline II & $\begin{array}{l}\text { 'Blue rubber nipples' - bluish, thin-walled, blood-filled sac. } \\
\text { This lesion is easily compressed and refills slowly upon re- } \\
\text { lease of pressure, and it usually presents with associated } \\
\text { pain and hyperhidrosis }\end{array}$ \\
\hline III $\quad \begin{array}{l}\text { Irregular blue-black macule or plaque that may be punctated } \\
\text { and rarely blanches on pressure }\end{array}$ \\
\hline
\end{tabular}

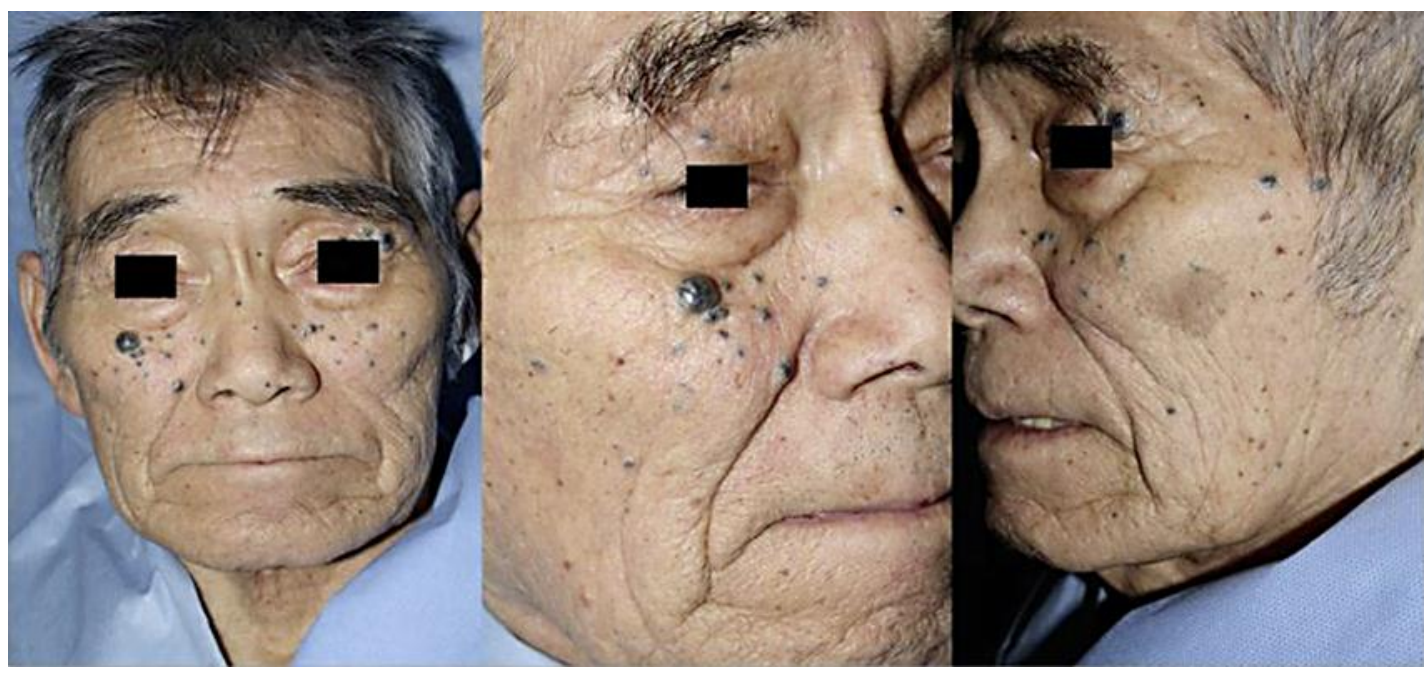

Fig. 1. Multiple, dark blue, compressive papules and nodules on the patient's face, ranging in size from 2 to $10 \mathrm{~mm}$. 


\section{Case Reports in Dermatology}

\begin{tabular}{l|l}
\hline \multicolumn{2}{l|}{ Case Rep Dermatol 2015;7:194-198 } \\
\hline DOI: $10.1159 / 000438664$ & $\begin{array}{l}\text { C 2015 S. Karger AG, Basel } \\
\text { www.karger.com/cde }\end{array}$ \\
\hline
\end{tabular}

Korekawa et al.: Blue Rubber Bleb Nevus Syndrome Showing Vascular Skin Lesions Predominantly on the Face

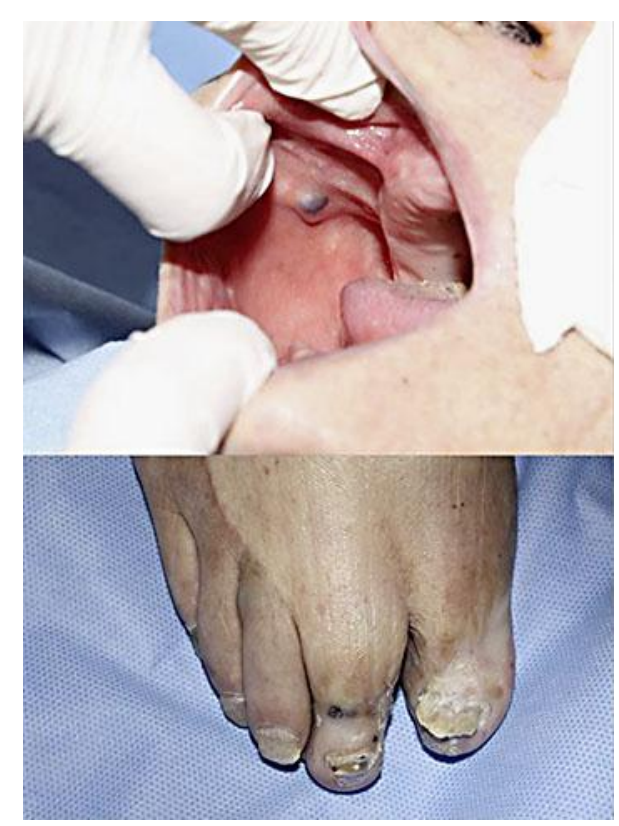

Fig. 2. Dark blue and compressive papules on the patient's right dorsal second toe (bottom) and buccal mucosa (top).
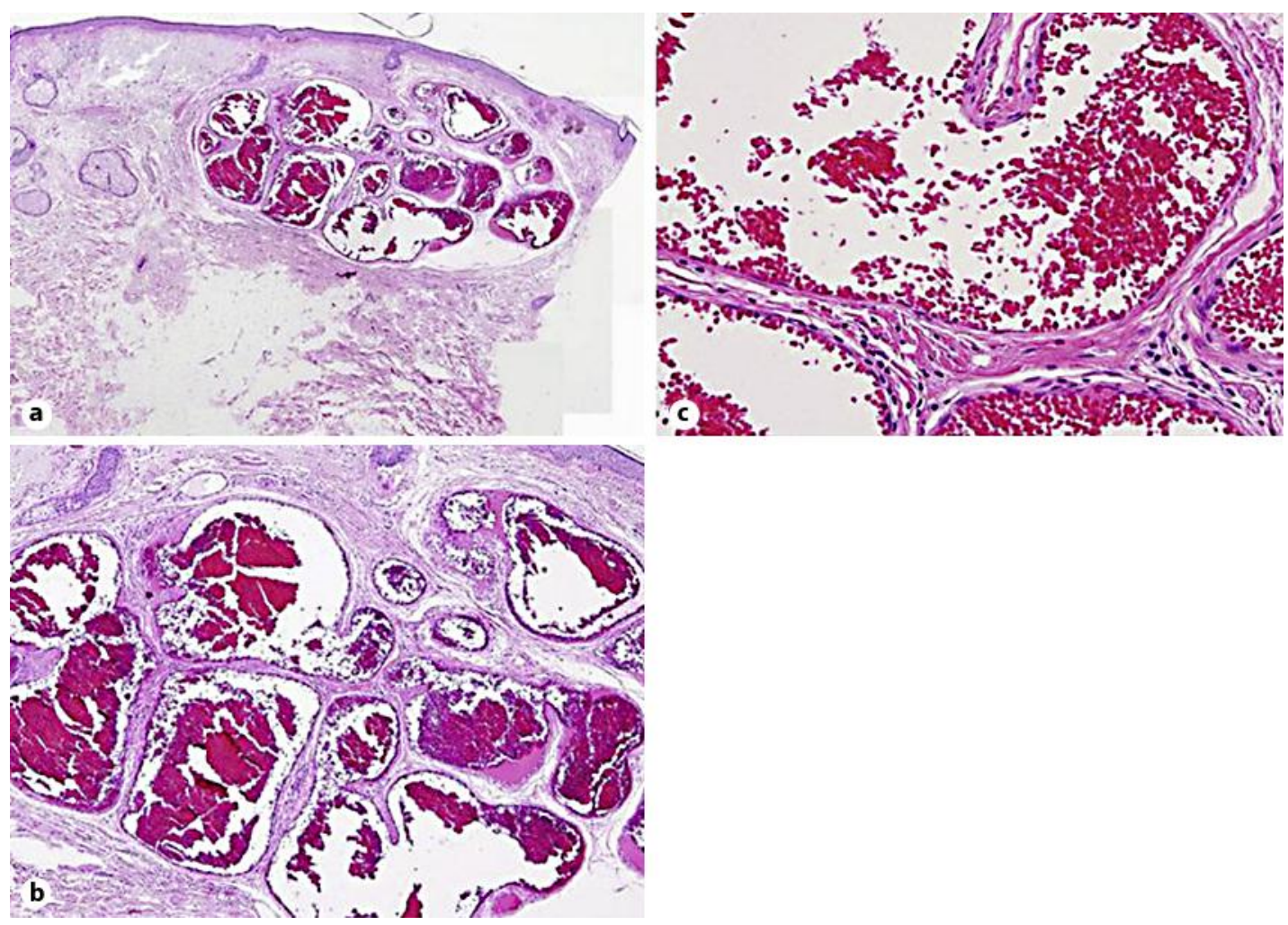

Fig. 3. a Dilated vascular spaces lined by normal epithelium in the dermis. $\mathbf{b}, \mathbf{c}$ The vascular space is surrounded by thin connective tissue. Lysed erythrocytes were observed within the vascular space. Hematoxylin and eosin staining. a Whole picture. $\mathbf{b} \times 40$. $\mathbf{c} \times 400$. 